\title{
Nitric Oxide Chemistry Effects in Hypersonic Boundary Layers
}

\author{
C. J. Arisman ${ }^{1}$, C.T. Johansen ${ }^{2}$ \\ University of Calgary, Calgary, $A B, T 2 N 1 N 4$
}

\begin{abstract}
Simulations of gas seeding into a hypersonic boundary layer flow were performed using OpenFOAM to investigate and quantify errors associated with quantitative planar laser induced fluorescence thermometry and velocimetry techniques. A modified version of the compressible rhoCentralFoam solver was used to simulate multicomponent chemically reactive flows. Simulations replicated conditions used in NASA Langley's 31-Inch Mach 10 facility with a wedge model oriented at various angles of attack with respect to the freestream flow in the test section. Adverse chemistry effects from the reaction of nitric oxide with molecular oxygen were investigated at various facility running conditions. Specifically, the effect of heat release on velocity and temperature profiles that would be obtained using the non-intrusive laser measurement techniques was assessed The effect of any potential adverse chemistry reactions was found to be negligible.
\end{abstract}

$\begin{array}{lll}\text { Nomenclature } & \\ A & = & \text { First Arrhenius reaction rate constant } \\ B & = & \text { Second Arrhenius reaction rate constant } \\ C & = & \text { Third Arrhenius reaction rate constant } \\ c_{p} & = & \text { Specific heat at constant pressure, } \mathrm{kJ} / \mathrm{kg} / \mathrm{K} \\ D_{i, j} & = & \text { Binary diffusion coefficient, } \mathrm{m}^{2} / \mathrm{s} \\ D_{i, m} & = & \text { Diffusion coefficient of species i into the mixture, } \mathrm{m}^{2} / \mathrm{s} \\ E_{a} & = & \text { Arrhenius reaction rate activation energy, } \mathrm{J} / \mathrm{mol} \\ h_{i} & = & \text { Sensible enthalpy of species } \mathrm{i}, \mathrm{kJ} / \mathrm{kg} \\ h_{s} & = & \text { Sensible enthalpy, } \mathrm{kJ} / \mathrm{kg} \\ I & = & \text { Identity matrix } \\ J_{i} & = & \text { Diffusion flux of species } \mathrm{i}, \mathrm{kg} / \mathrm{m}^{2} / \mathrm{s} \\ k & = & \text { Thermal conductivity, } \mathrm{W} / \mathrm{m} / \mathrm{k} \\ k_{N O} & = & \text { Reaction rate of NO, } \mathrm{l}^{2} / \mathrm{mols} \mathrm{s}^{2} \mathrm{~s} \\ L_{1 / 2} & = & \text { Half-life length scale, } \mathrm{m} \\ L_{d} & = & \text { Computational domain length, } \mathrm{m} \\ L_{s i m} & = & \text { Local simulation length scale, } \mathrm{m} \\ M a & = & \text { Mach number } \\ M_{i} & = & \text { Molar mass of species i, } \mathrm{kg} / \mathrm{kmol} \\ P & = & \text { Pressure, Pa } \\ & & \end{array}$

${ }^{1}$ Graduate Student, Department of Mechanical and Manufacturing Engineering, Member AIAA.

${ }^{2}$ Assistant Professor, Department of Mechanical and Manufacturing Engineering, Member AIAA. 


$\begin{array}{lll}P_{\text {stag }} & = & \text { Stagnation pressure, Pa } \\ R & = & \text { Ideal gas constant, } \mathrm{J} / \mathrm{K} / \mathrm{mol} \\ R_{i} & = & \text { Mass fraction source of species i } \\ S_{h} & = & \text { Enthalpy source, } \mathrm{kJ} / \mathrm{s} / \mathrm{m}^{3} \\ t & = & \text { Time, } \mathrm{s} \\ T & = & \text { Temperature, } \mathrm{K} \\ t_{1 / 2} & = & \text { Half-life, } \mathrm{s} \\ T_{\text {stag }} & = & \text { Stagnation Temperature, } \mathrm{K} \\ u & = & \text { Velocity, } \mathrm{m} / \mathrm{s} \\ Y_{i} & = & \text { Mass fraction of species i } \\ \alpha & = & \text { Thermal conductivity divided by specific heat at constant pressure, } \mathrm{kg} / \mathrm{m} / \mathrm{s} \\ \beta & = & \text { Oblique shock angle } \\ \theta_{p l a t e} & = & \text { Plate angle of attack } \\ \mu & = & \text { Viscosity, } \mathrm{kg} / \mathrm{m} / \mathrm{s} \\ \rho & = & \text { Density, } \mathrm{kg} / \mathrm{m}^{3} \\ \sigma_{i, j} & = & \text { Average species collision diameter, } \mathrm{m} \\ \tau & = & \text { Viscous stress tensor, Pa } \\ X_{N O} & = & \text { Mol fraction of NO } \\ X_{N O, i} & = & \text { Initial mol fraction of NO } \\ X_{O_{2}} & = & \text { Mol fraction of O2 } \\ X_{O_{2}, i} & = & \text { Initial mol fraction of O2 } \\ \Omega_{d} & = & \text { Diffusion collision integral } \\ \Omega_{v} & = & \text { Viscous collision integral } \\ & & \end{array}$

\section{I.Introduction}

$\mathrm{T}$

$\neg$ HE seeding of nitric oxide (NO) is a common technique used to facilitate planar laser-induced fluorescence (PLIF) data collection in hypersonic flows. In flows where a fluorescent species is not present it is required that a species be seeded into the flow to facilitate the PLIF technique. NO is often preferred when the bulk flow medium is air as its thermophysical properties and molecular size are close to that of the species present in air; reducing adverse effects of seeding [1]. However, the seeding of NO introduces other potential adverse effects that need to be quantified. $\mathrm{NO}$ reacts with $\mathrm{O}_{2}$ in air at low temperatures in a termolecular, exothermic, reaction [2]. This reaction is of particular concern in hypersonic wind tunnels that use NO PLIF as a flow visualization technique because the flow temperatures are often quite low due to the large expansion required to achieve high Mach numbers. The NASA Langley Research Center's 31-Inch Mach 10 Air Tunnel is an example of such a facility that produces low temperature freestream conditions where NO chemistry could be a problem. There have been several experiments in that facility where NO PLIF was used to study the transition to turbulence [3-6]. Quantifying any potential chemistry effects is important for the interpretation of the results of those works.

In these prior NO PLIF experiments, a planar, 20 degree wedge was placed into the test section and NO gas was seeded through a slot on the model to allow for PLIF images to be obtained downstream. A series of protuberance shapes with various heights were placed on the wedge surface and PLIF flow visualization and quantitative molecular tagging velocimetry (MTV) measurements were obtained. Figure 1 shows the wedge model, gas seeding slot, and a cylindrical trip that was used during several of the experiments [5]. In this facility, the wind tunnel stagnation pressure and model angle of attack (AoA) can be varied to replicate different edge conditions, including Reynolds number, on the wedge surface. 


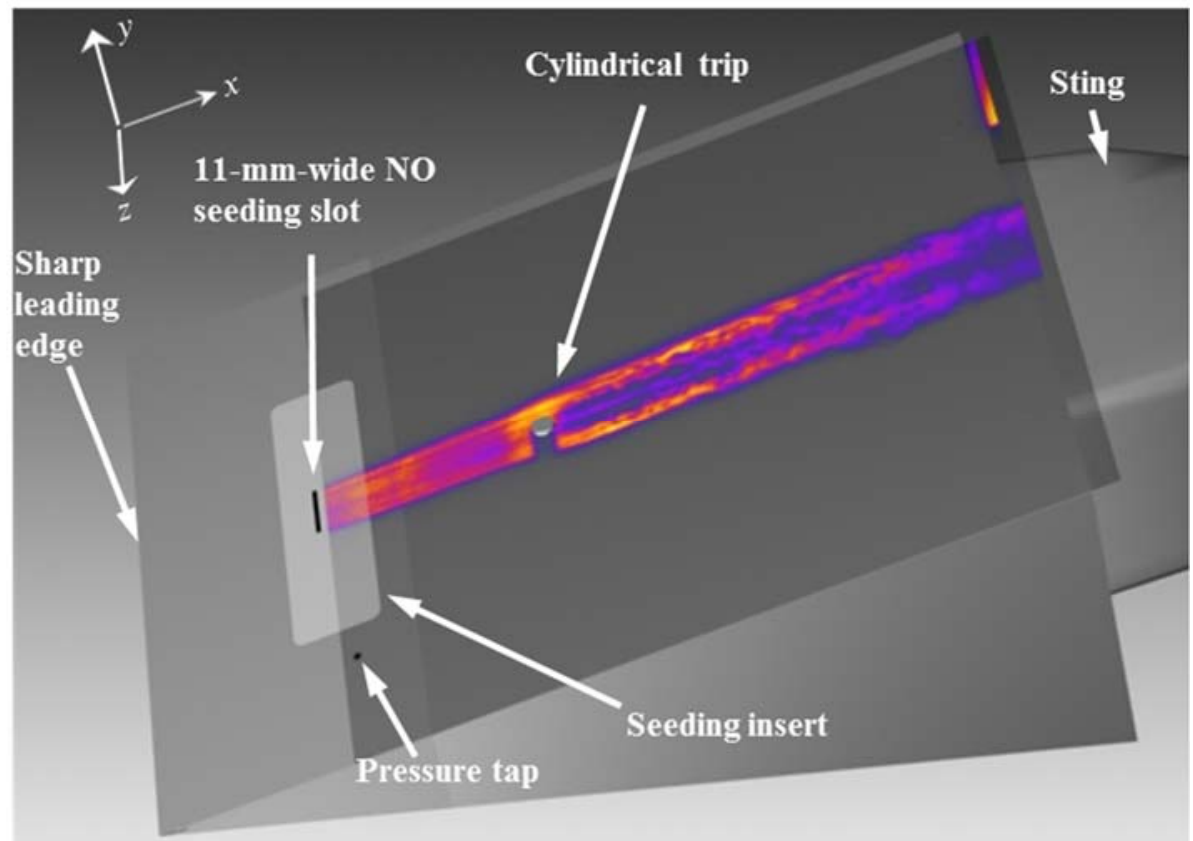

Fig. 1 Schematic of wedge model, indicating the gas seeding slot and a cylindrical-shaped trip. Reproduced from Ref. [5]

The need to quantify negative effects associated with the gas seeding process motivated prior a numerical study comparing several typical PLIF seed gases injected from the wedge model [1]. The gases simulated included NO, Krypton $(\mathrm{Kr})$, and Iodine $\left(\mathrm{I}_{2}\right)$. Although $\mathrm{Kr}$ and $\mathrm{I}_{2}$ are non-reactive with oxygen, they have a much higher molecular weight (MW) than NO and air, resulting in large differences in their respective thermophysical properties. For a given mass flow rate of seeded gas, it was found that NO had the largest dispersion rate and penetrated the furthest into the boundary layer, which is beneficial for PLIF imaging. In addition, the seeding of NO had the smallest adverse effect on velocity and temperature profiles downstream. The study, however, did not investigate the effects of model AoA, or chemistry effects of NO on the boundary layer profiles. Therefore, the focus of the current study is to investigate these effects. A methodology of assessing these effects analytically is also presented.

\section{CFD Solver}

The open source CFD software, OpenFOAM v2.2.x, was used with a modified version of the rhoCentralFoam solver for the simulations [7]. The rhoCentralFoam solver is a density based solver which uses a custom finite volume discretization scheme that allows it to accurately simulate flow discontinuities while still producing a non-oscillatory solution [8]. To facilitate this study the rhoCentralFoam solver was extended to create the rhoCentralReactingFoam solver which simulates multiple component reacting mixtures. Solver modifications were validated against identical simulations performed in ANSYS Fluent [9].

\section{A. Governing Equations}

The conservation of mass, momentum (neglecting body forces), and energy used by the rhoCentralReactingFoam solver are defined as:

$$
\begin{gathered}
\frac{\partial \rho}{\partial \mathrm{t}}+\nabla \cdot(\rho \mathrm{u})=0 \\
\frac{\partial(\rho \mathrm{u})}{\partial \mathrm{t}}+\nabla \cdot\left(\rho \mathrm{u}^{2}\right)=-\nabla \mathrm{P}+\nabla \cdot \tau \\
\frac{\partial\left(\rho \mathrm{h}_{\mathrm{s}}\right)}{\partial \mathrm{t}}+\nabla \cdot\left(\rho \mathrm{uh}_{\mathrm{s}}\right)=\nabla \cdot\left[\alpha \nabla \mathrm{h}_{\mathrm{s}}+\sum_{\mathrm{i}=1}^{\mathrm{n}} \mathrm{h}_{\mathrm{i}} \mathrm{J}_{\mathrm{i}}\right]+\frac{\mathrm{DP}}{\mathrm{Dt}}+\nabla \cdot(\tau \cdot \mathrm{u})+\mathrm{S}_{\mathrm{h}}
\end{gathered}
$$


where $\rho, u, P, h_{s}, T, S_{h}$ are the gas density, velocity, pressure, sensible enthalpy, temperature and enthalpy source respectively. $\alpha$ is the thermal diffusivity and is defined as $\frac{k}{c_{p}}$ where $k$ is the thermal conductivity and $c_{p}$ is the specific heat at constant pressure. The viscous stress tensor, $\tau$, in vector form is defined as:

$$
\tau=\mu\left(\nabla u+(\nabla u)^{T}-\frac{2}{3} \nabla \cdot u I\right)
$$

where $\mu$ is the viscosity and $I$ is the unit tensor. The viscous stress tensor is $2 \mu$ multiplied by the deviatoric component of the deformation gradient tensor.

The enthalpy transport term, $\sum_{i=1}^{n} h_{i} J_{i}$, has been included in the energy equation, which allows for variable Prandtl, Schmidt, and Lewis numbers. The thermal conductivity is calculated from a modified Euken correction[10]:

$$
k=\mu\left(\frac{15}{4}-1.32\left(\frac{c_{p}}{R}-\frac{5}{2}\right)\right) R
$$

Specific heat values for NO, $\mathrm{I}_{2}$ and $\mathrm{Kr}$ were taken from the NIST-JANAF tables [11]. The viscosity is calculated based on kinetic theory from the Chapman-Cowling relationship [12]:

$$
\mu=2.6693 * 10^{6} \frac{\sqrt{M T}}{\sigma \Omega_{v}}
$$

where $\Omega_{v}$ is the viscous collision integral. The transport of multiple species mass fraction $\left(Y_{i}\right)$ for both solvers, neglecting thermal diffusion, is given by the following conservation equation:

$$
\frac{\partial\left(\rho Y_{i}\right)}{\partial t}+\nabla \cdot\left(\rho u Y_{i}\right)=-\nabla \cdot J_{i}+R_{i}
$$

where $J_{i}$ is the diffusion flux of species $i$ and is defined as:

$$
\mathrm{J}_{\mathrm{i}}=-\rho \mathrm{D}_{\mathrm{i}, \mathrm{m}} \nabla \mathrm{Y}_{\mathrm{i}}
$$

The diffusion coefficient, $D_{i, m}$, for species $i$ in the mixture is given by Wilke's equation [13]:

$$
D_{i, m}=\frac{1-X_{i}}{\sum_{j, j \neq i}^{n} \frac{X_{j}}{D_{i, j}}}
$$

where $X_{i}$ is the molar fraction of species $i$ and $D_{i, j}$ is the binary diffusion coefficient, which was calculated using the Chapman-Enskog equation [14]:

$$
D_{i, j}=0.00188 \frac{\left[T^{3}\left(\frac{1}{M_{a}}+\frac{1}{M_{b}}\right)\right]^{\frac{1}{2}}}{P \sigma_{a b}^{2} \Omega_{d}}
$$

The average species collision cross section, $\sigma_{a b}$, is based on tabulated values published by Svehla [15] and $\Omega_{d}$ is the diffusion collision integral. For the diffusion coefficient calculation $P$ is in bar. $M_{a}$ and $M_{b}$ are the molecular weights of species $a$ and $b$ respectively. Mixture properties are calculated based on a mass weighted average of the individual species properties. It should be noted that the methodology used by NASA to compute wind tunnel conditions includes real-gas law effects to account for high-density effects in the reservoir [16]. However, since only the test section is being simulated at low density conditions the gas has been assumed to be ideal. 


\section{B. Simulation Setup}

The computational domain is based on the wedge model used in the experiments performed in NASA Langley's 31-Inch Mach 10 facility [3-5,17,18]. Figure 2 shows a schematic of the wind tunnel facility. Seen in the figure is the test section; the viewing section is shown on the left hand side of the figure with the camera setup. The laser system can be seen on the right of the facility.

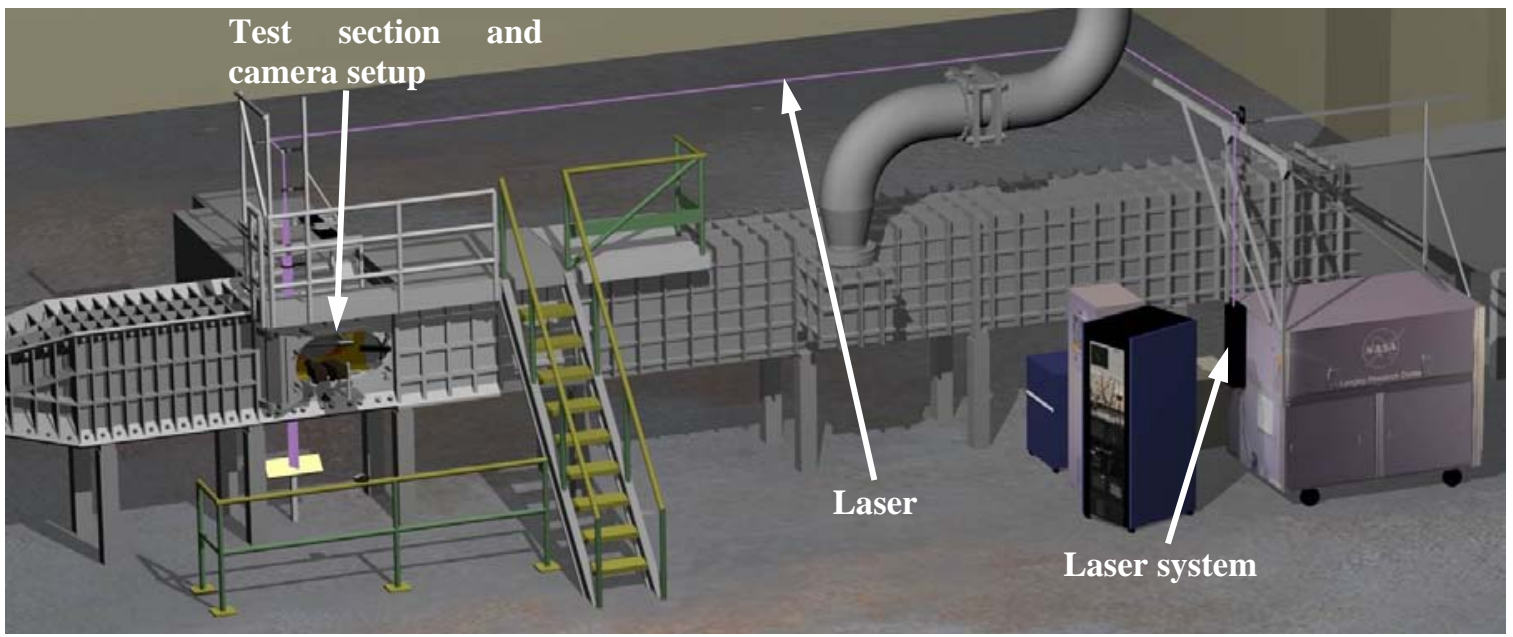

Fig. 2 NASA Langley 31-Inch Mach 10 Air Tunnel Facility with PLIF systems. Reproduced from Ref. [3]

A schematic of the computational domain relative to the wedge model and sting is shown in Fig. 3. The domain is two dimensional, $200 \mathrm{~mm}$ in length ( $x$ direction) and $30 \mathrm{~mm}$ in height ( $y$ direction). The origin of the coordinate system is at the leading edge of the wedge. The gas is seeded from a slot that is $0.81 \mathrm{~mm}$ in the streamwise direction and $11 \mathrm{~mm}$ in the span wise direction (perpendicular to the flow) located $29.4 \mathrm{~mm}$ downstream of the leading edge. An inlet section for the seed gas equal to four seed slot widths in length was included in the computational domain.

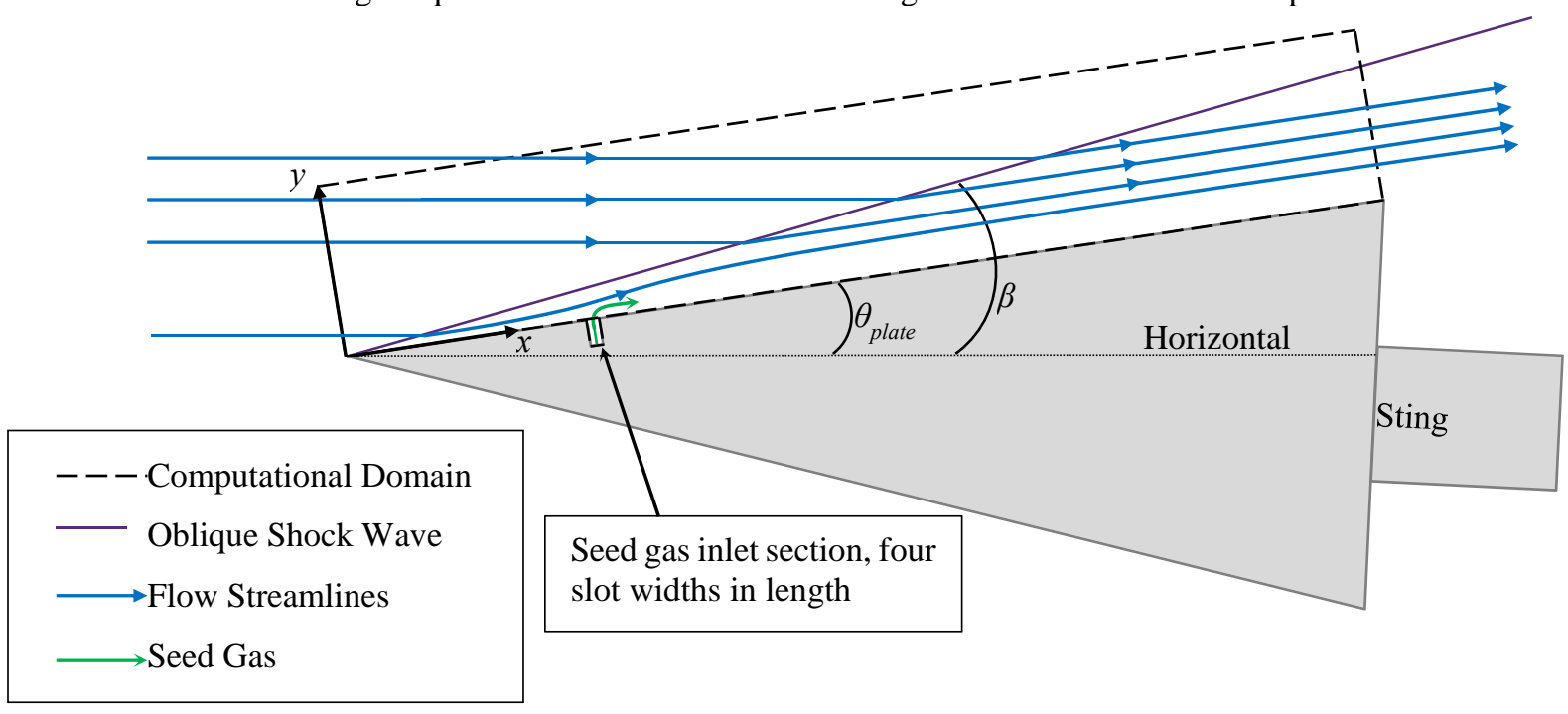

Fig. 3 Computational domain (not to scale)

The bottom of the domain is aligned with the top surface of the wedge. The plate angle of attack $\left(\theta_{\text {plate }}\right)$ is controlled by specifying the inlet velocity (direction) on the top and left boundaries. Constant pressure, temperature, and velocity values of $P=68.4 \mathrm{~Pa}, T=52.3 \mathrm{~K}$, and $U=1407.3 \mathrm{~m} / \mathrm{s}(\mathrm{Ma}=9.7)$ are specified at the inlet boundaries which correspond to one of the experimental run conditions. These freestream values were calculated from the facility stagnation pressure $\left(P_{\text {stag }}=350 \mathrm{psi}, 2.41 \mathrm{MPa}\right)$ and temperature $\left(T_{\text {stag }}=1000 \mathrm{~K}\right)$ values specified in one of the representative tests. Equations relating the stagnation conditions to the freestream values are outlined in the literature [16]. In the simulations, the wedge was oriented at angles of $\theta_{\text {plate }}=5^{\circ}$ and $1^{\circ}$. The bottom wall is specified as a no-slip condition, zero normal gradient in pressure and fixed temperature $(T=314 \mathrm{~K})$. The fixed temperature was determined from the 
experimental data at this condition. The right outflow boundary is specified as zero normal gradient for the temperature, velocity and pressure boundary conditions.

The walls of the seed gas inlet section were modeled as slip boundaries and given a constant static temperature of $314 \mathrm{~K}$. The total temperature of the pipe inflow boundary was calculated based on the desired mass flow rate and the pressure at the jet outlet. The mass flow rate, $\dot{m}$, was equal to $3 \mathrm{mg} / \mathrm{s}$, which is equivalent to 150 standard cubic centimeters per minute (sccm). This is typical for NO PLIF in NASA Langley Research Center's 31-Inch Mach 10 Air Tunnel facility.

\section{Mesh Sensitivity Results}

Figure 4 shows the rhoCentralBinaryFoam mesh, which consists of approximately 1.2 million nodes. The grid is refined near the leading edge, at the gas injection slot and near the bottom wall. The cells are then graded, increasing in size as the domain moves away from the seed slot and the bottom wall. Further refinement beyond the 1.2 million nodes had a negligible impact on the simulation results.
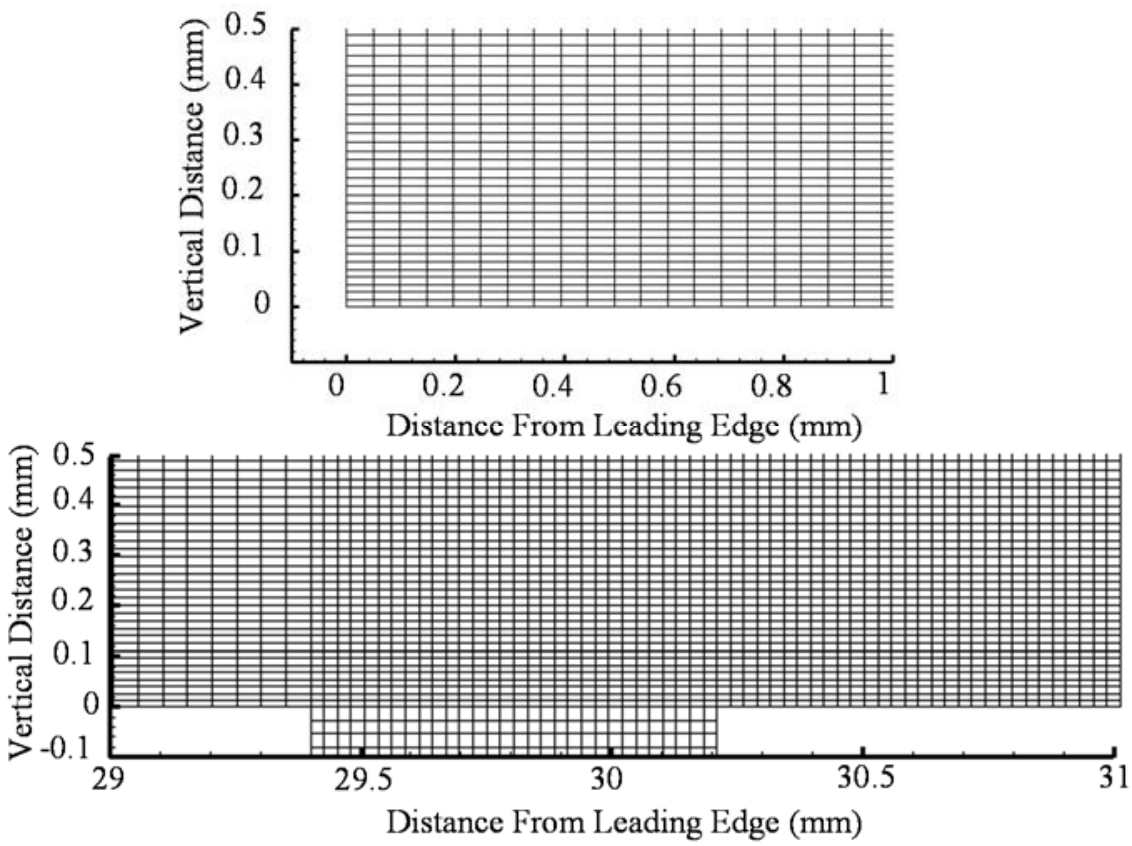

Fig. 4 Computational grid near leading edge (top) and at gas seeding location (bottom).

\section{NO Chemistry}

The static temperature in the test section of the 31-Inch Mach 10 facility is low ( 52 K) because of the large expansion that occurs in the nozzle. It is known that NO reacts with Oxygen $\left(\mathrm{O}_{2}\right)$ at low temperatures in a termolecular reaction to form nitrogen dioxide defined as:

$$
\mathrm{O}_{2}+2 \mathrm{NO}=>2\left(\mathrm{NO}_{2}\right)
$$

The reaction is of concern due to its rapidity at low temperatures and exothermic nature. The heat generated from the reaction has the potential to alter the thermodynamic properties of the boundary layer. The reaction rate has been measured experimentally by Olbregts [2]. An adapted version of his empirical formula in an Arrhenius rate form is given as:

$$
\mathrm{k}_{\mathrm{NO}}=10^{\mathrm{A}} \mathrm{T}^{\mathrm{B}} \exp \left[\frac{\mathrm{E}_{\mathrm{a}}}{\mathrm{RT}}\right]
$$

where $E_{a}$ is the activation energy given by

$$
\mathrm{E}_{\mathrm{a}}=\mathrm{RCln}(10)
$$


$A, B$, and $C$ are empirical constants with values of $-5.18,2.70$ and 700 , respectively. The formula given in Eq. (12) has units of liters ${ }^{2}$ mols $^{-2}$ seconds $^{-1}$. A plot of the reaction rate as a function of temperature is shown in Fig. 5 . The empirical formula is valid for temperatures between $226 \mathrm{~K}$ and $758 \mathrm{~K}$ [2].

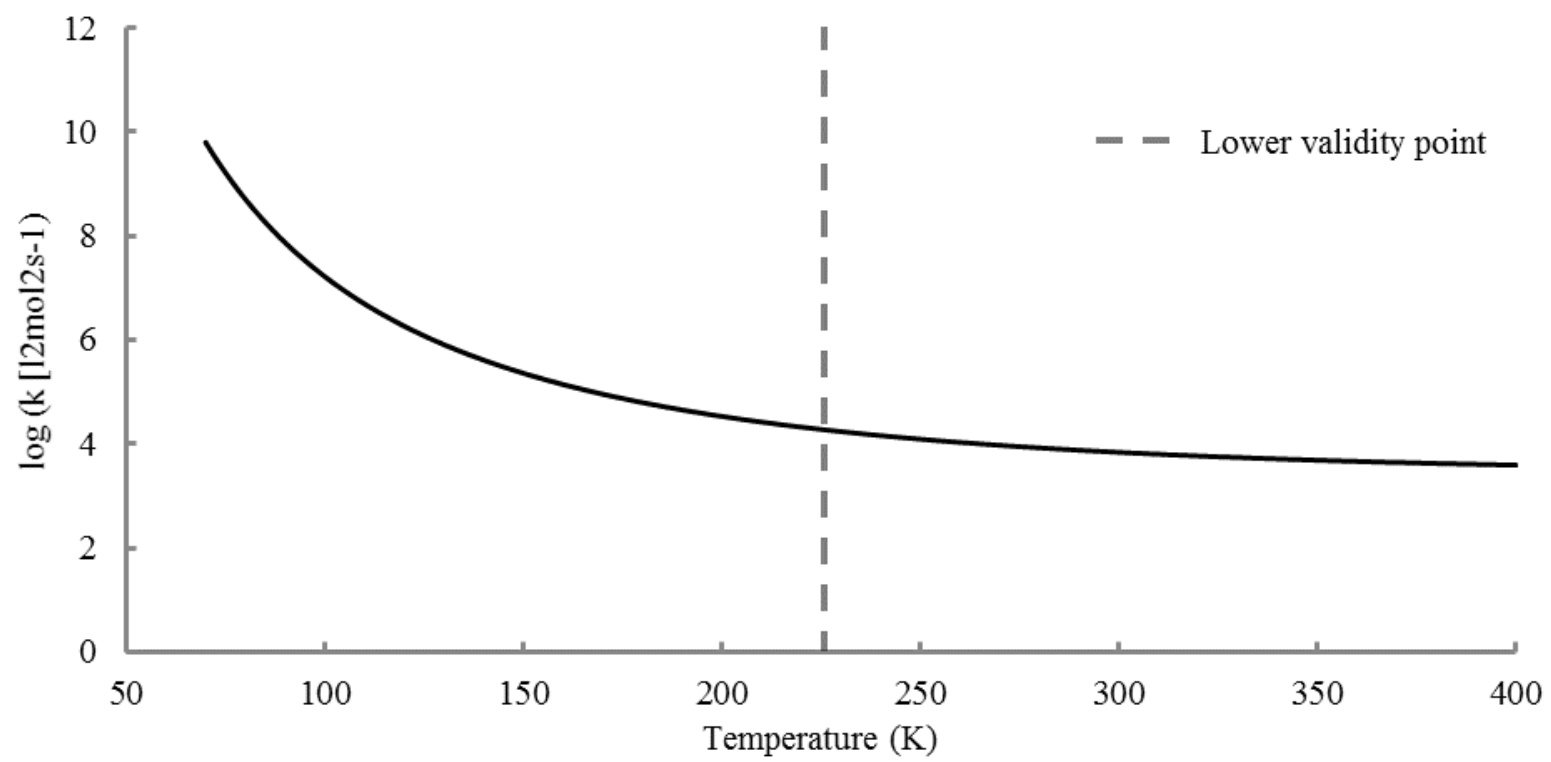

Fig. 5 Effect of temperature on rate of reaction of NO. Reproduced from Ref. [9]

In the following calculations, the reaction rate model was extrapolated to low temperatures to account for the relatively cold edge conditions near the edge of the boundary layer. However, the temperature in the boundary layer where most of the NO is concentrated is approximately $300 \mathrm{~K}$ to $400 \mathrm{~K}$ in the 5 degree case.

\section{A. NO Half-life}

The importance of NO chemistry in the flow was estimated through a half-life calculation. The half-life is then compared to the residence time of the flow based on analytical pressure, temperature, and velocity calculations. Finally, the half-life calculation is applied to CFD simulations with and without gas seeding. It can be shown that the half-life of NO, $t_{1 / 2}$, can be written as [9]:

$$
\mathrm{t}_{1 / 2}=\frac{\mathrm{R}^{2} \mathrm{~T}^{2}}{\mathrm{P}^{2}} \frac{\mathrm{X}_{\mathrm{NO}, \mathrm{i}}\left(1+\ln \left[\frac{4 \mathrm{X}_{\mathrm{O}, \mathrm{i}}-\mathrm{X}_{\mathrm{NO}, \mathrm{i}}}{2 \mathrm{X}_{\mathrm{O}, \mathrm{i}}}\right]\right)-2 \mathrm{X}_{\mathrm{O}, \mathrm{i}}}{-\mathrm{k}_{\mathrm{NO}}\left(2 \mathrm{X}_{\mathrm{O}, \mathrm{i}}-\mathrm{X}_{\mathrm{NO}, \mathrm{i}}\right)^{2} \mathrm{X}_{\mathrm{NO}, \mathrm{i}}}
$$

where $X$ is the mol fraction of the subscript species. Assumed in the derivation of the above half-life expression is that $\mathrm{O}_{2}$ is in excess and varies as the reaction proceeds. Once the half-life of $\mathrm{NO}$ is known it can be compared to residence time in the computational domain. If the half-life is long compared to the residence time of the flow then the flow can be approximated as non-reacting. Figures 6 and 7 show contour plots of temperature and pressure obtained from the OpenFOAM simulation with no gas seeding. Pressure and temperature are directly related to reactant concentration and reaction rate. Figure 8 shows the ratio of half-life length scale $\left(L_{1 / 2}\right)$ normalized by the local simulation length scale $\left(L_{\text {sim }}\right)$ :

$$
\frac{\mathrm{L}_{1 / 2}}{\mathrm{~L}_{\mathrm{sim}}}=\frac{\mathrm{U}_{\mathrm{x}} * \mathrm{t}_{1 / 2}}{\mathrm{~L}_{\mathrm{d}}-\mathrm{x}}
$$

where $U_{x}$ is the $x$ velocity, $L_{\text {sim }}$ is the length of the computational domain and $x$ is the horizontal distance from the origin (leading edge). Because of the large range in $L_{1 / 2}$ calculations, Fig. 8 is shown on a log scale. The half-life length scale was chosen since the reaction is asymptotic at low NO concentrations. It provides an order of magnitude analysis. A large value of $L_{1 / 2} / L_{\text {sim }}$ indicates that the flow is non-reacting. Also of interest in the figures are the various flow features including the oblique shock and the development of the thermal boundary layer. 


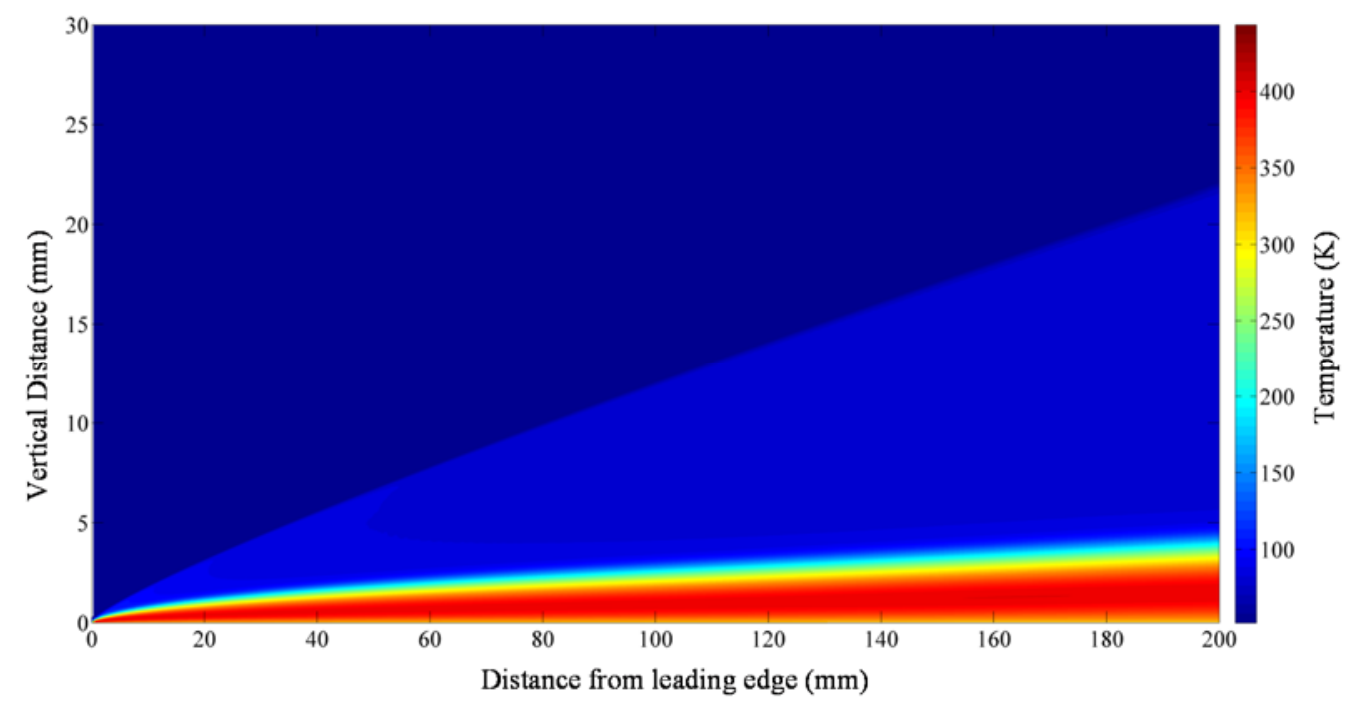

Fig. 6 Simulated temperature distribution. $P_{\text {stag }}=350$ psi; $T_{\text {stag }}=1000 \mathrm{~K} ; \theta_{\text {plate }}=5^{\circ}$. Reproduced from Ref. [9]

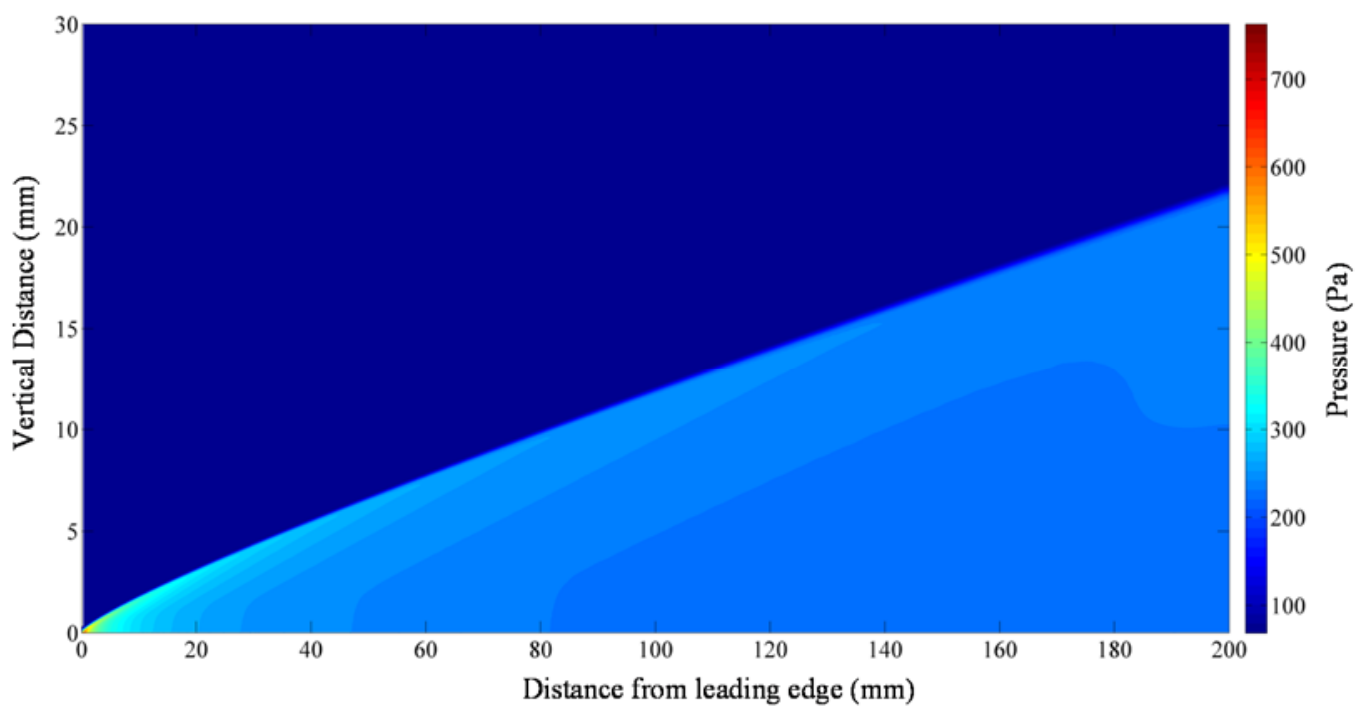

Fig. 7 Simulated pressure distribution. $P_{\text {stag }}=350 \mathrm{psi} ; \mathrm{T}_{\text {stag }}=1000 \mathrm{~K} ; \theta_{\text {plate }}=5^{\circ}$. Reproduced from Ref. [9]

The minimum value of the $\mathrm{L}_{1 / 2} / \mathrm{L}_{\text {SIM }}$ ratio is 0.84 and occurs in the freestream at the computational domain inlet where the temperature is $52 \mathrm{~K}$. This indicates that if $\mathrm{NO}$ was present in the freestream, it would react within the computational domain. However, NO is seeded at the wall and is unable to penetrate much beyond the velocity boundary layer, which is far away from the leading shock wave. Therefore, the lowest expected value of $L_{1 / 2}$ is at the edge of the boundary layer, which roughly corresponds to the edge conditions after the oblique shock wave. The pressure and temperature conditions at this location can be found from the oblique shock relations [19]. 


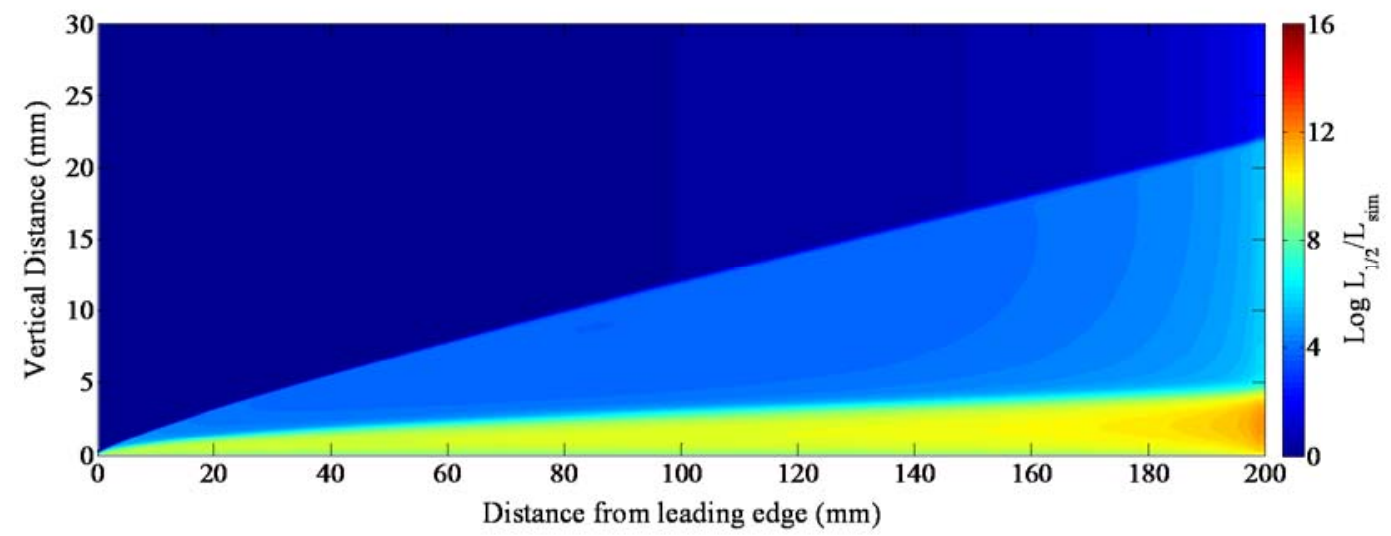

Fig. 8 Simulated $\mathrm{L}_{1 / 2} / \mathrm{LsIm}$ distribution based on Eq. (15) $P_{\text {stag }}=350 \mathrm{psi} ; \mathrm{T}_{\text {stag }}=1000 \mathrm{~K} ; \theta_{\text {plate }}=5^{0} ; X_{\mathrm{NO}, \mathrm{i}}=0.1$; $\mathrm{X}_{02, \mathrm{i}}=\mathbf{0 . 2}$. Reproduced from Ref. [9]

The minimum half-life length scale for different wedge angles and wind tunnel stagnation conditions can then be estimated from the post-shock conditions and Eq. (14). The results, over the range of typical stagnation pressures in NASA Langley's 31-Inch Mach 10 facility, are shown in Fig. 9. Cases which have been simulated are indicated with filled-in dots. From the figure it can be seen that the NO reaction has the potential to alter the thermodynamic characteristics at shallower wedge angles and at higher stagnation pressures. The dashed line indicates the position $L_{1 / 2} / L_{\text {sim }}=1$ and corresponds to the approximate limit where $\mathrm{NO}$ reactions will occur within the field of view of the wedge model or computational domain. Two major assumptions are that the NO concentration boundary layer is thicker than the thermal boundary layer and that the Olbregts reaction can be reliably extrapolated to these lower temperatures.

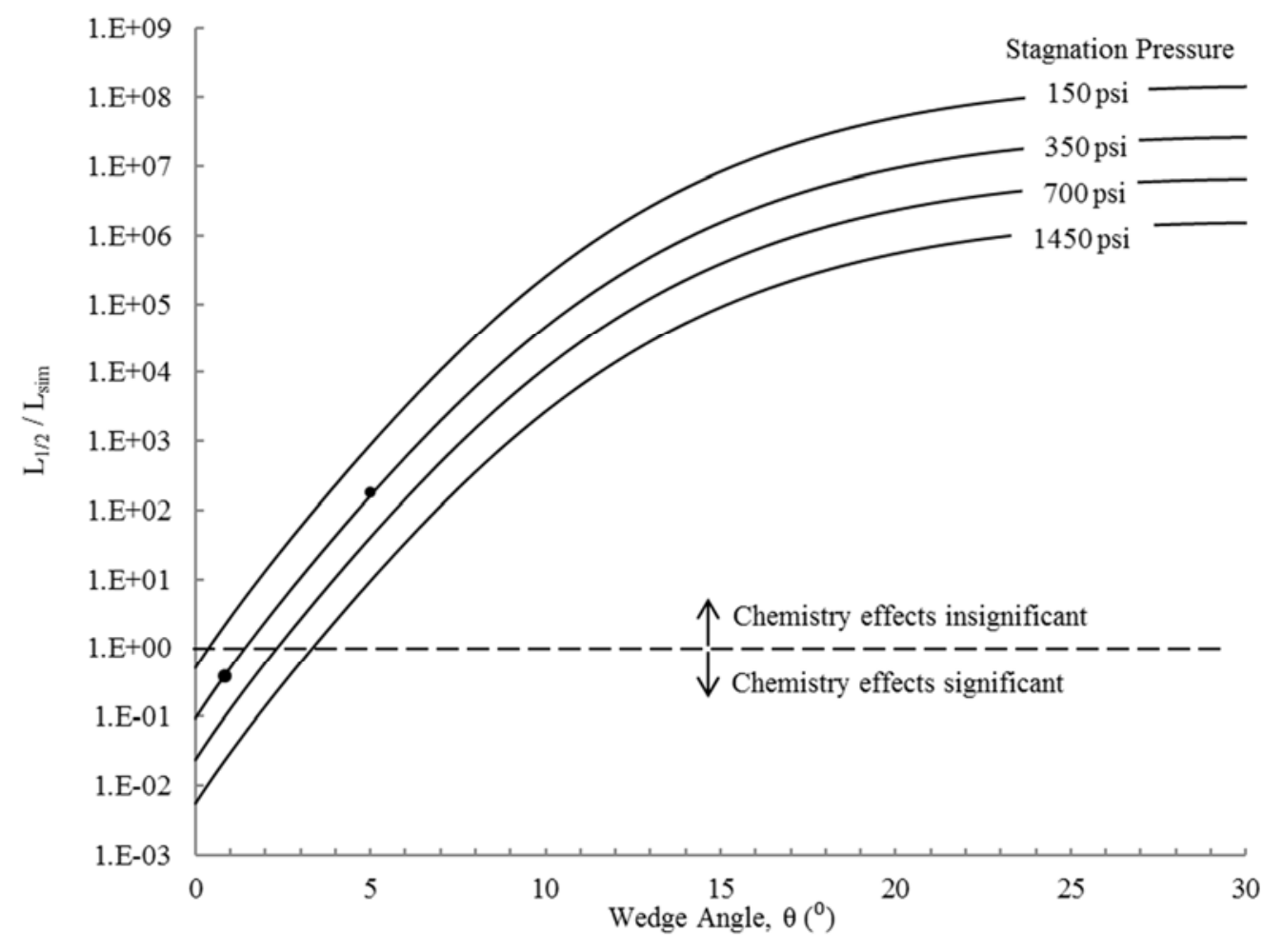

Fig. 9 Effect of NASA's 31-Inch Mach 10 facility stagnation pressure on the length scales of NO chemistry. Eq. (15) used for $L_{1 / 2}$ calculation. Reproduced from Ref. [9] 
To account for non-uniform NO distributions, life time calculations were performed on gas seeding simulations without chemical reactions. Figure 10 shows the distribution of $L_{1 / 2}$ based on the simulated NO gas seeding case performed using the rhoCentralReactingFoam solver at wedge angles of $\theta_{\text {plate }}=5^{\circ}$ and $1^{\circ}$ at an NO seed rate of 150 sccm. Also shown on the graphs are isotherms for the thermal boundary layer. The color scheme has been changed from the previous figures to better accentuate the regions where $L_{1 / 2}$ is at a minimum. Additionally, the ratios are presented on a logarithmic scale. It should be noted that the thermal boundary layer continues beyond the isotherms plotted. The oblique shock in the vicinity of the seed slot makes plotting lower temperature isotherms difficult. The post-shock freestream temperatures are approximately $80 \mathrm{~K}$ and $63 \mathrm{~K}$ for $\theta_{\text {plate }}=5^{\circ}$ and $1^{\circ}$ respectively.
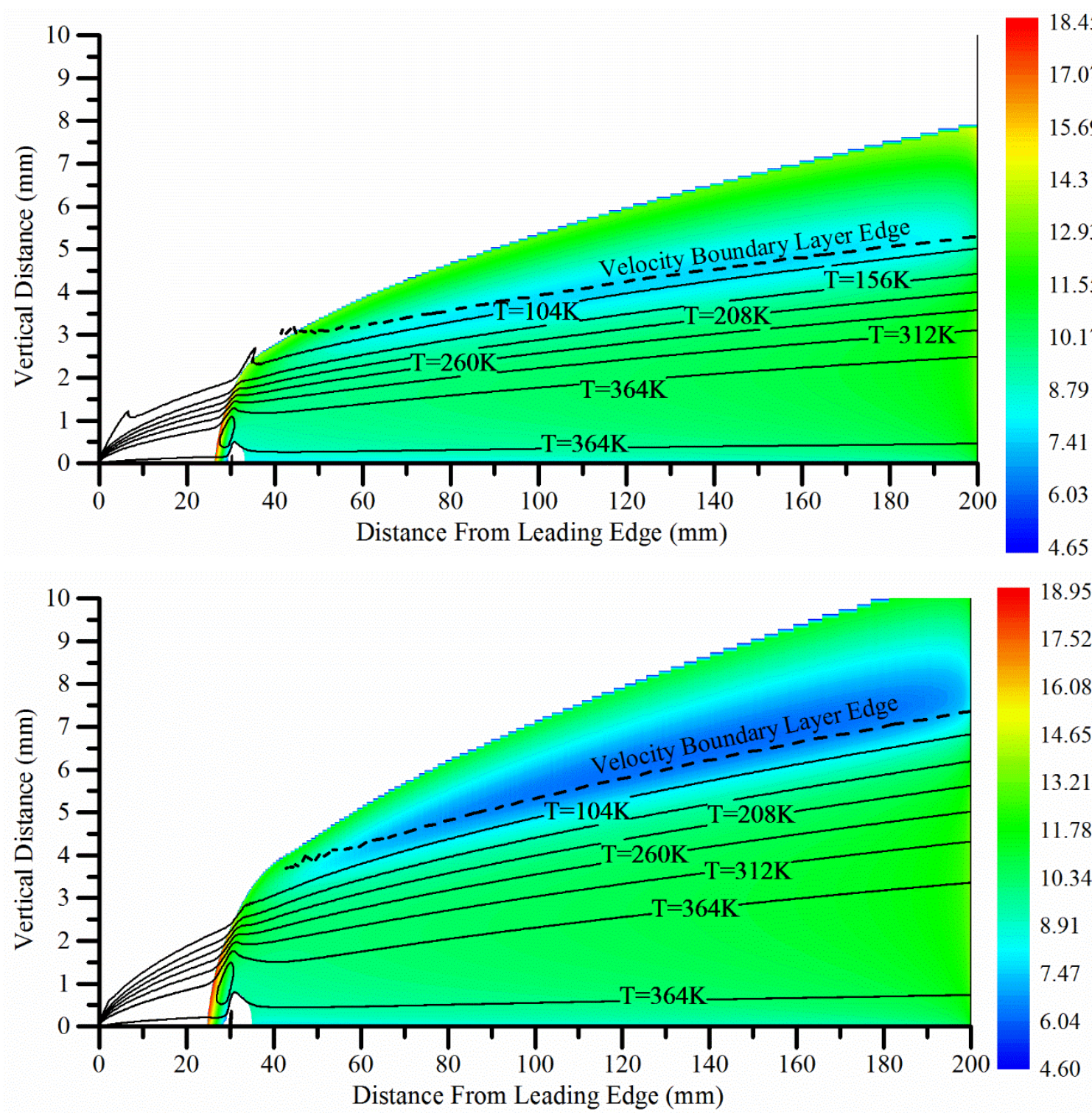

Fig. $10 L_{1 / 2} / L_{S I M}$ distribution based on simulated NO gas seeding and Eq. (15). $\theta_{\text {plate }}=5^{\circ}$ (top) $1^{0}$ (bottom). Isolines of temperature shown.

With gas seeding, the concentration of NO is the largest near the injection slot where the gas temperature is near the wall temperature $(314 \mathrm{~K})$. Although the NO reaction rate coefficient, $k_{N O}$, is large at the edge of the boundary layer, concentration levels of NO decrease such that $L_{1 / 2}$ values effectively increase. Since there are negligible NO concentration levels outside of the boundary layer, the $L_{1 / 2} / L_{\text {sim }}$ contours were cropped at those locations. For $\theta_{\text {plate }}=$ $5^{\circ}$, minimum $L_{1 / 2}$ values occur in the immediate vicinity of the injection slot where the concentration of NO is highest. 
The next lowest values are near the edge of the boundary layer, where the temperature is low. For $\theta_{\text {plate }}=1^{0}$ the lowest values are near the edge of the thermal boundary layer, but still within it. This is due to the fact that NO does not diffuse beyond the thermal boundary layer in noticeable quantities for either plate angle. Overall, the values of $L_{1 / 2} / L_{s i m}$ are large enough that no significant chemical reactions are expected.

\section{B. Reacting Simulations}

Simulations of NO gas seeding with chemical reactions were performed with rhoCentralReactingFoam at a plate angle of 5 degrees and a stagnation pressure of $350 \mathrm{psi}$. A contour plot of the $\mathrm{NO}_{2}$ mass fraction with overlaid isotherms is shown in Fig. 11. As expected, most of the $\mathrm{NO}_{2}$ forms near the seed slot with some additional $\mathrm{NO}_{2}$ forming near the edge of the boundary layer. Peak $\mathrm{NO}_{2}$ locations correspond reasonably well with the predicted minimum $L_{1 / 2} / L_{s i m}$ values shown in Fig. 10. It was found that the heat release from these reactions had a negligible impact on the temperature distribution. Note that the production of $\mathrm{N}_{2} \mathrm{O}_{4}$ from $\mathrm{NO}_{2}$ in an exothermic reaction was not included in this work. The limiting reaction at these conditions is the conversion of $\mathrm{NO}$ and $\mathrm{O}_{2}$ into $\mathrm{NO}_{2}$. Even when assuming that all of the $\mathrm{NO}_{2}$ produced converts immediately to $\mathrm{N}_{2} \mathrm{O}_{4}$, the additional heat generated is not sufficient to have any discernable impact on the flow.

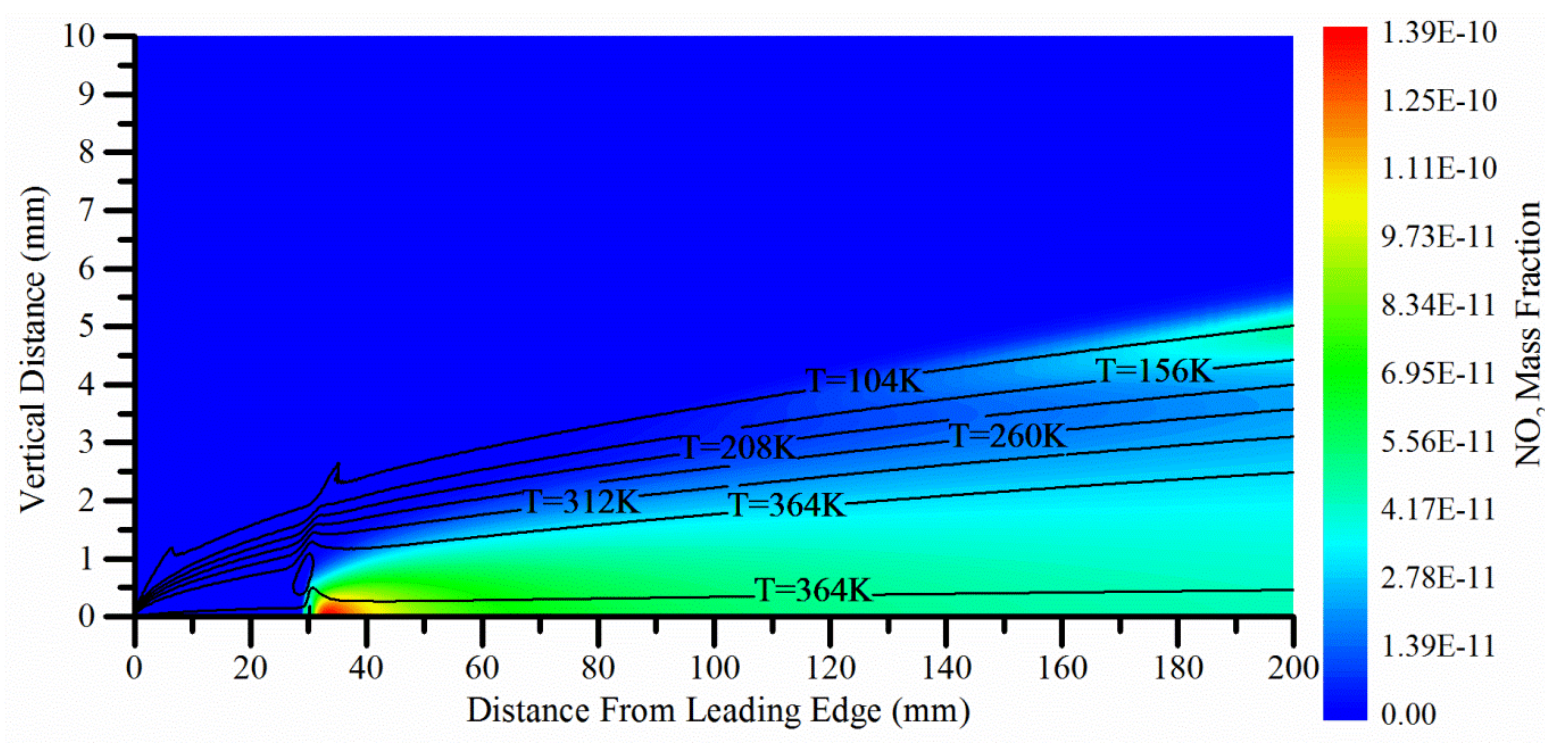

Fig. 11 Simulated $\mathrm{NO}_{2}$ distribution $P_{\text {stag }}=350 \mathrm{psi}$; $\mathrm{T}_{\text {stag }}=1000 \mathrm{~K} ; \theta_{\text {plate }}=5^{\circ}$; Isolines of temperature shown.

Simulations at lower plate angles of attack $\left(\theta_{\text {plate }}=1^{\circ}\right)$ were also performed. It was expected that the lower static temperature at the boundary layer edge would increase the reaction rate. The predicted $\mathrm{NO}_{2}$ contours at this condition are shown in Fig. 12. As expected, peak $\mathrm{NO}_{2}$ concentrations are highly correlated with predicted minimum $L_{1 / 2} / L_{\text {sim }}$ values (Fig. 10), which occurs at the edge of the thermal boundary layer. However, since concentration levels of NO decrease rapidly downstream of the seeding slot, the effect of chemical reactions on the temperature distribution is still negligible. Similar observations were found for all positive plate angles simulated in this work. Although possible in the Langley 31-Inch Mach 10 facility, negative plate angles were not simulated in this study. Small aerodynamic perturbations in the boundary layer were observed as a result of the NO injection. This effect was already reported in a previous study of non-reacting gas seeding simulations [1]. 


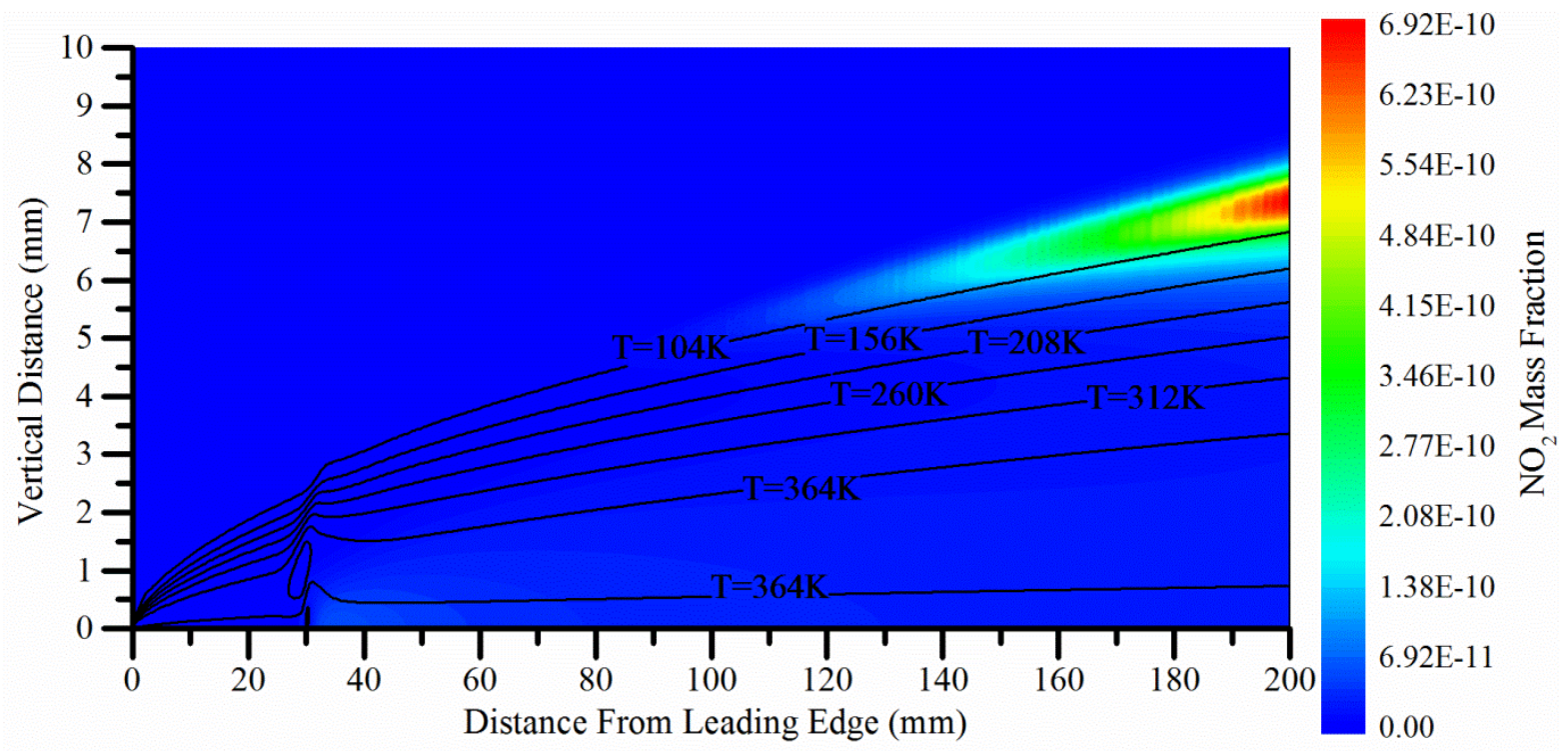

Fig. 12 Simulated $\mathrm{NO}_{2}$ distribution $\mathrm{P}_{\text {stag }}=350 \mathrm{psi} ; \mathrm{T}_{\text {stag }}=1000 \mathrm{~K} ; \theta_{\text {plate }}=1^{\circ}$; Isolines of temperature shown.

Although it was determined that the effects of NO chemical reactions on the flow are negligible at all positive plate angles, some extrapolation of the Olbregt NO reaction rate to approximately $70 \mathrm{~K}$ was required. Recall that Olbregt reported reaction rate values over a range of $226 \mathrm{~K}$ and $758 \mathrm{~K}$. Therefore, the overall reaction rate was artificially increased by a factor of $10^{3}$ for the $\theta_{\text {plate }}=1^{\circ}$ condition to observe any adverse effects on the flow. All of the other flow conditions were kept constant. The location of peak NO formation was found to be the same as in Fig. 12. Larger amounts of $\mathrm{NO}_{2}$ were produced at the edge of the boundary layer but $\mathrm{NO}_{2}$ formation and heat release from the reaction were still found to be negligible. Peak NO concentrations under the $10^{3}$ reaction rate were on the order of $10^{-7}$.

At very large reaction rates, the production of $\mathrm{NO}_{2}$ is limited by the mixing process of $\mathrm{NO}$ and $\mathrm{O}_{2}$. Figure 13 shows $\mathrm{NO}_{2}$ distributions where the reaction rate is increased by a factor of $10^{12}$, ensuring that the reaction is complete within the field of view. The peak concentrations of $\mathrm{NO}_{2}$ shift away from the edge of the boundary layer (Fig. 12) to a location just downstream of the seed slot.

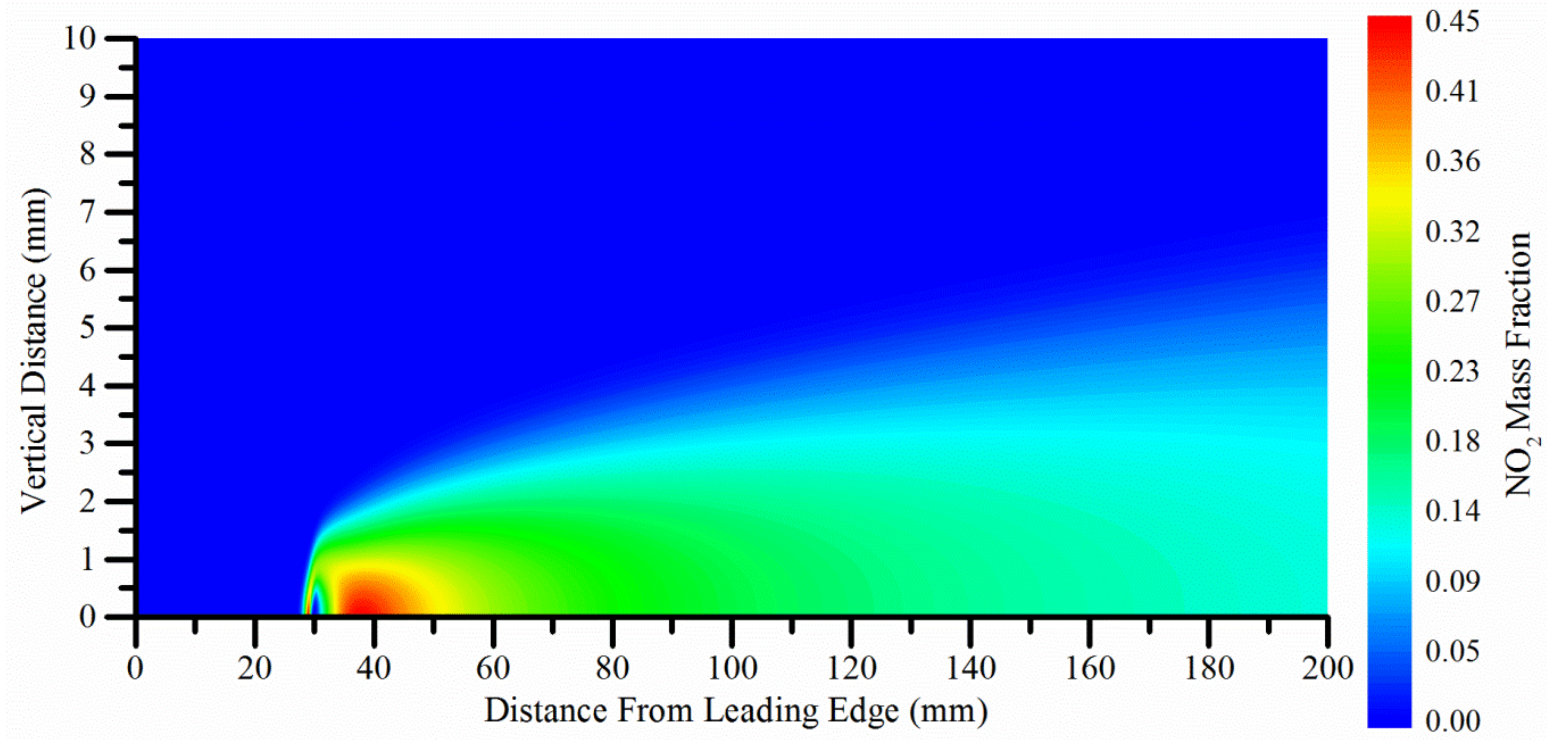

Fig. 13 Simulated $\mathrm{NO}_{2}$ distribution; $P_{\text {stag }}=350 \mathrm{psi} ; \mathrm{T}_{\text {stag }}=1000 \mathrm{~K} ; \theta_{\text {plate }}=1^{\circ}$; Reaction rate increased by a factor of $10^{12}$; 
In this case, the reaction does have adverse effects on the temperature distribution. Figure 14 shows the temperature difference between the non-reacting and mixing limited reaction simulations. Temperature deviations upwards of $316 \mathrm{~K}$ are observed downstream of the seed slot. This indicates the maximum adverse effects that could occur (assuming an infinitely fast reaction rate) with this level of NO injection. Curiously, high rates of thermal diffusion further downstream allow temperature profiles to return close to their non-reactive case distributions.

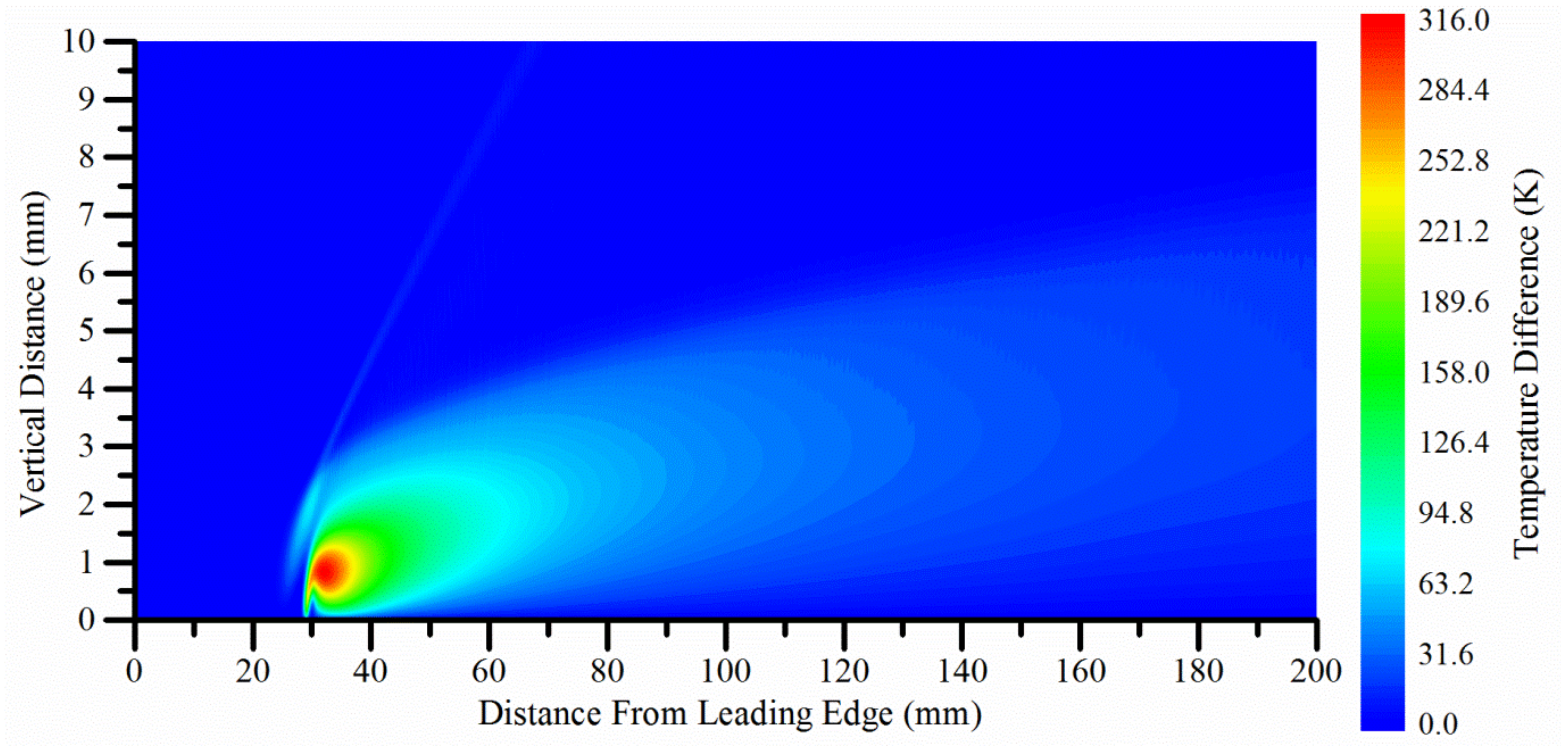

Fig. 14 Simulated temperature distribution; $P_{\text {stag }}=350 \mathrm{psi} ; T_{\text {stag }}=1000 \mathrm{~K} ; \theta_{\text {plate }}=1^{\circ}$; Reaction rate increased by a factor of $10^{12}$;

\section{Discussion}

When observing distributions of $\mathrm{NO}_{2}$ and the reaction rate for the $\theta_{\text {plate }}=1^{\circ}$ case, it is evident that the temperature of the flow governs the reaction rate magnitude. As a result the bulk of the reactions take place near the edge of the boundary layer where the temperature is lowest. For $\theta_{\text {plate }}=5^{\circ}$ the effect of both concentration and temperature are important as reactions occur both near the seed slot and at the edge of the boundary layer. Concentration and temperature have nearly equal effects on the reaction rate at those locations, resulting in $\mathrm{NO}_{2}$ production of similar magnitudes. Because NO never diffuses beyond the thermal boundary layer in significant quantities, very little reactions occur. The temperature difference due to the heat released by the chemical reaction in the vicinity of the seeding slot was found to be less than $0.5 \%$ compared to the nonreactive simulation temperature for both cases.

The analytical model for NO chemistry that assumes a uniform seed gas distribution (Fig. 9) indicates that the edge conditions for the $\theta_{\text {plate }}=1^{\circ}$ case will result in a static temperature low enough such that chemistry effects will be important. This model assumes that NO escapes beyond the thermal boundary layer and is exposed to the edge conditions. This is however not the case as the seeding simulations indicate that NO does not escape the thermal boundary layer and therefore are not exposed to favorable conditions for $\mathrm{NO}_{2}$ formation. In addition, the concentration of $\mathrm{NO}$ at the edge of the boundary layer is low enough such that only a negligible amount of $\mathrm{NO}_{2}$ forms. While more $\mathrm{NO}_{2}$ is produced near the edge of the boundary layer when the wedge angle of attack is decreased, significant quantities fail to form. However, the analytical model that uses a non-uniform seed gas distribution (Fig. 10) is able to predict the location of the highest concentration of $\mathrm{NO}_{2}$. As a result, if a reasonable estimate of the distribution of NO is known, the impact of the $\mathrm{NO}_{2}$ reaction can be estimated using the analytical length scale ratio presented in Eq. (15). For significant reactions to occur, the concentration boundary layer would need to be thicker than the thermal boundary layer. However, previous work [1] indicates that higher NO seeding rates are not required to achieve sufficient signalto-noise ratios from the PLIF system in the 31-Inch Mach 10 facility. It is possible that at negative wedge angles, where Prandtl-Meyer expansion would occur, would result in adverse NO chemistry effects.

Simulations with artificially amplified reaction rates help to assess the uncertainty involved in extrapolating Olbregt's NO reaction rate to low temperatures $(<226 \mathrm{~K})$. Even with a reaction rate amplified by $10^{3}$, simulations show that the chemistry effects are still negligible. When the reaction rate was amplified to very high levels $\left(10^{12}\right)$, the reaction rate was limited by mixing and adverse chemistry effects near the seed slot were observed. 


\section{Conclusion}

The local concentration levels of $\mathrm{NO}, \mathrm{O}_{2}$ and static temperature are the main factors that drive the reaction of NO seeded into a hypersonic boundary layer on a wedge model at positive angles of attack in NASA Langley's 31-Inch Mach 10 facility. Half-life predictions based on uniform NO concentration levels are not reliable in predicting the importance of chemistry effects for locally seeded flows. However, half-life predictions based on simulated NO distributions are able to predict the location and relative magnitude of chemistry effects.

Large magnitudes of the local reaction rate coefficient driven by low static temperatures at the edge of the boundary layer are counter-balanced by low concentrations of NO; as a result the reaction rate was found to be negligible for wedge angles greater than and equal to $1^{\circ}$ and with an $\mathrm{NO}$ seed rate of $150 \mathrm{sccm}$ or less. While some $\mathrm{NO}_{2}$ is produced at these conditions, the total amount of heat produced due to chemical reactions is negligible. NO has a very high dispersal rate but is unable to penetrate beyond the thermal boundary layer; resulting in negligible chemical reactions.

Simulations with artificially high reaction rates indicate that if significant reactions were to occur, they would mainly occur near the wall and seed slot. In this case, the extrapolation of Olbregt's empirical formula below $226 \mathrm{~K}$ is unnecessary to predict the reacting flow. Even with the reaction rate amplified by a factor of $10^{3}$, reactions of NO had a negligible impact on the boundary layer flow properties at these conditions. At a reaction rate artificially inflated by a factor $10^{12}$, adverse chemistry effects are observed. The bulk of the reactions occur near the seed slot as the reactions become dominated by the mixing of reactants rather than the static temperature.

\section{Acknowledgments}

The authors would like to thank Jeff Balla and Paul Danehy for providing valuable information regarding the halflife calculations, wind tunnel experiment, and the laser imaging setup. This work was supported by the Natural Sciences and Engineering Research Council of Canada (NSERC).

\section{References}

[1] Johansen, C., and Danehy, P., "Numerical investigation of PLIF gas seeding for hypersonic boundary layer flows," 50th AIAA Aerospace Sciences Meeting including the New Horizons Forum and Aerospace Exposition, AIAA 2012-1057, Nashville, TN, 2012.

[2] Olbregts, J., "Termolecular Reaction of Nitrogen Monoxide and Oxygen: A Still Unsolved Problem," International Journal of Chemical Kinetics, Vol. 17, No. 8, 1985, pp. 835-848.

[3] Medford, T., Danehy, P., Jones, S., et al., "Stereoscopic Planar Laser-Induced Fluorescence Imaging at 500 kHz," 49th AIAA Aerospace Sciences Meeting including the New Horizons Forum and Aerospace Exposition, AIAA 2011-985, Orlando, FL, 2011.

[4] Bathel, B., Danehy, P., Inman, J., et al., "Hypersonic Laminar Boundary Layer Velocimetry with Discrete Roughness on a Flat Plate," 40th Fluid Dynamics Conference and Exhibit, AIAA 2010-4998, Chicago, IL, 2010.

[5] Danehy, P., Ivey, C., Inman, J., et al., "High-Speed PLIF Imaging of Hypersonic Transition over Discrete Cylindrical Roughness," 48th AIAA Aerospace Sciences Meeting Including the New Horizons Forum and Aerospace Exposition, AIAA 2010-703, Orlando, FL, 2010.

[6] Danehy, P., Ivey, C., Bathel, B., et al., "Orbiter BLT Flight Experiment Wind Tunnel Simulations: Nearfield Flowfield Imaging and Surface Thermography," 48th AIAA Aerospace Sciences Meeting Including the New Horizons Forum and Aerospace Exposition, AIAA 2010-1571, Orlando, FL, 2010.

[7] OpenCFD Ltd, "2014, http://www.openfoam.org," [online] [retrieved .

[8] Greenshields, C. J., Weller, H. G., Gasparini, L., et al., "Implementation of semi-discrete, non-staggered central schemes in a colocated, polyhedral, finite volume framework, for high-speed viscous flows," International Journal for Numerical Methods in Fluids, Vol. 63, No. 1, May 2010, pp. 1-21 doi: 10.1002/fld.2069.

[9] Arisman, C., Johansen, C. T., Galuppo, W., et al., "Nitric Oxide Chemistry Effects in Hypersonic Boundary Layers," 43rd Fluid Dynamics Conference, AIAA 2013-3104, San Diego, CA, 2013.

[10] Hirschfelder, J. O., Curtiss, C. F., Bird, R. B., et al., Molecular theory of gases and liquids, Wiley New York, 1954.

[11] National Institute of Standards and Technology, "NIST-JANAF Thermochemical Tables," [online] http://kinetics.nist.gov/janaf/ [retrieved .

[12] Chapman, S., and Cowling, T. G., The mathematical theory of non-uniform gases: an account of the kinetic theory of viscosity, thermal conduction and diffusion in gases, Cambridge university press, 1970. 
[13] Asano, K., Mass Transfer: From Fundamentals to Modern Industrial Applications, Wiley-VCH Verlag GmbH \& Co. KGaA, Weinheim, FRG, 2006.

[14] Brodkey, R. S., and Hershey, H. C., Transport phenomena: a unified approach, Brodkey publishing, 2003.

[15] Svehla, R. A., "Estimated viscosities and thermal conductivities of gases at high temperatures," NASA Technical Report R-132, Lewis Research Center, Cleveland, 1962.

[16] Hollis, B. R., Real-gas flow properties for NASA Langley Research Center aerothermodynamic facilities complex wind tunnels, NASA Contractor Report 4755, Langley Research Center, 1996.

[17] Bathel, B. F., Danehy, P. M., Inman, J. A., et al., "Multiple velocity profile measurements in hypersonic flows using sequentially-imaged fluorescence tagging," 48th AIAA Aerospace Sciences Meeting Including the New Horizons Forum and Aerospace Exposition, AIAA 2010-1404, Orlando, FL, 2010.

[18] Jiang, N., Webster, M., Lempert, W. R., et al., "MHz-rate nitric oxide planar laser-induced fluorescence imaging in a Mach 10 hypersonic wind tunnel," Applied optics, Vol. 50, No. 4, 2011, pp. A20-A28.

[19] John, J. E. A., and Keith, T. G., Gas Dynamics, Pearson Prentice Hall, 2006. 